\title{
The Evil of Banality: Moby Dick vs. the Extreme Machine
}

\author{
Carol Vanderveer Hamilton
}

Today Americans are overcome not by the sense of endless possibility but by the banality of the social order they have erected against it.

\section{-Christopher Lasch}

\section{Extreme Machines}

American fantasies of upward and outward mobility, endless space, vast and remote landscapes, and possessive, libertarian-style individualism are all closely linked to the automobile. Only a few decades ago, no American automobile was more desirable or iconic than a compact sports convertible with a powerful engine. Designed to rival European sports cars like the Porsche James Dean died in, the Ford Thunderbird, first manufactured in 1954, deliberately evoked the American continent-prairies, canyons, Native Americans. The T-bird convertible became the ideal automobile for that quintessentially American genre, the road movie, and as late as 1991 it was the vehicle driven by Thelma and Louise in their flight to Mexico. In the first decade of the new century the West is still where television ads are filmed, and the open road is still an American fantasy, but the popularity of the

Carol Vanderveer Hamilton has published articles in Oxford German Studies, The Conradian, Anarchist Studies, and in the anthology Turn of the Century. Her poems have appeared in The Paris Review, Salmagundi, and The North American Review, among others. A book of poems entitled Blindsight is forthcoming from Carnegie Mellon University Press. She is currently working on an article entitled "George W. Bush Does Not Exist." 
compact sports car has given way to that of the "light truck," a category that includes the SUV, the minivan, and the pick-up truck. It is therefore not surprising that the culture industry has abandoned the muscle car for what some websites have dubbed the "extreme machine."

For several years now, writers and pundits have been discussing the explosive popularity of the extreme machine. Keith Bradsher's High and Mighty announces its thesis in its subtitle: The World's Most Dangerous Vehicles and How They Got That Way. In a 2001 article in Harper's Magazine, Paul Roberts observes, "Detroit has always used our insecurities to sell us cars. For decades we bought cars because we hoped they would make us look 'fast' or 'sporty' or 'sexy' or 'bad'"(73). In recent years, Roberts continues, Detroit noted the creeping popularity of the pick-up truck among what he calls "urban and suburban cowboy wanna-bes" (71) members of the white-collar middle class who long to be perceived as rugged, active, and useful. Automakers proceeded to capitalize on the popular "aesthetic of functionality," Roberts speculates, by inventing a new, larger version of the jeep, bolting the body onto the chassis of a pick-up truck, and naming it the "sport utility vehicle." The SUV was only the beginning; the trend toward larger vehicles soon produced the enormous truck and the civilian Hummer.

Analyses like those of Roberts and Bradsher are smart and informative, but they tend to dwell on the worldly disadvantages of the extreme machine, neglecting its psychic, almost phantasmatic appeal. In this article I propose that we view the contemporary infatuation with extreme machines not as evidence of the perennial urge to go west or back to nature, but as the latest cathexis to a long series of symbols that - from Herman Melville's era on - have acquired their value and resonance because they appeal to a populace afflicted with possessive individualism, American exceptionalism, and a darker, less conscious psychological malaise. Because the hypertrophic vehicle does seem a case of protesting too much - of psychological "inflation," of overcompensation for some individual or collective deficit-it is worth considering what insecurities it defends against, what fantasies it engages, what it "symbolizes," both psychologically and culturally.

First, it is necessary to understand why the extreme machine has come to occupy a privileged site in the imagination of the American consumer. Underlying the fantasy of ruggedness, it is surely the light truck's most obvious feature, its size, which has entranced its many purchasers. Auto manufacturers compete to see who can manufacture the most enormous vehicle. "Go Big or Go Home!" proclaims a print ad for the aptly-named 2004 Nissan Titan. The enormous SUV, too capacious for its actual use, suggests a new manifestation of Veblen's "conspicuous consumption." Conspicuous waste is one mark of high caste, and consumer goods that claim sheer utility also always, Veblen argues, possess an element of waste. Ostentation is another marker of conspicuous consumption. The extreme machine fulfills both criteria: its size and interior opulence make it ostentatious (who is not taken aback upon seeing a Hummer on a suburban street?) and its waste of gasoline and space demonstrate that its owner has money to burn. The light truck is the new, more portable version of the Newport "cottage" so characteristic of a previous Gilded Age. 
Much as possession of a Porsche or Ford Mustang promised to transform a door-to-door salesman into James Dean, the extreme machine promises to turn a sedentary office worker into Jim Bowie or Calamity Jane. It declares that its owner is adventurous, practical, and perpetually on the verge of going white-water rafting. We might expect the driver of such a vehicle to be lean, fit, and attractively weathered, clad in climbing boots and khaki clothes from Timberland and Patagonia. In television commercials and print ads, the extreme machine is shown in some remote setting, usually out West - on top of a butte, crossing a desert, or bouncing through a forest. It is pictured full of outdoor gear-canoes, kayaks, bicycles. It bears adventurous names: Expedition, Explorer, Navigator, X-Terra, Outback, Tundra, Trailblazer, Tahoe, Avalanche. The brochure for the more aptly named 2001 Chevrolet Suburban even quoted Walden: "I went to the woods because I wished to live deliberately, to front only the essential facts of life" (Roberts 69).

Extreme machines have become the leviathans of American suburbs and highways. Larger every year, the extreme machine may, as the aforementioned title High and Mighty suggests, provide its driver with a sense of the marginality of smaller vehicles and, by extension, their drivers. He literally looks down on them, and therefore perhaps does so figuratively as well. The extreme machine confers upon its owner the sense of a powerful self, safe from the car-jackers of the urban wilderness, immune to the vicissitudes of fatal collisions, remote from involvement in the negligible existence of small beings like pedestrians and cyclists. Encased in this gigantic metal carapace, the driver imagines herself as menacing and invulnerable as Robocop. The fantasy of power conceals fantasies of fear: that the city is dangerous, that the only way to defend oneself from other drivers is to overwhelm them, that hostility is the norm and cooperation the exception. Thus the extreme machine manifests its driver's own attitudes, but as psychological projections. It is the driver who feels hostile, isolated, frightened, and entitled, who scorns the considered opinions and reasonable needs of her fellow citizens.

\section{American Symbols}

And of all these things, the Albino whale was the symbol. -Melville, Moby-Dick

"Symbolism," wrote Charles Feidelson, "is the coloration taken on by the American literary mind under the pressure of American intellectual history" (43). Focusing on the literature of the American Renaissance, Feidelson considered such richly ambiguous literary symbols as Melville's albino whale; the lilac, star, and bird of Whitman's "When Lilacs Last by the Dooryard Bloom'd"; Hawthorne's scarlet letter; Emerson's book of nature and transparent eyeball; and Poe's House of Usher. For all these writers, Feidelson writes, symbolism was a means of knowing and understanding the world - an epistemology. The meaning of any individual symbol was not static but "accreted" as various fictional characters observed and interpreted it. Our writers' creative fascination with complex, resonant symbols, Feidelson proposed, distinguishes American literature from the more social and historical 
narratives of British and European literature.

In this article I am suggesting that Feidelson's approach be appropriated for the contemplation and understanding of extra-literary phenomena like the extreme machine. As Russell Reising points out, Feidelson's "historical premise - that symbolism arose at a particular historical moment — could generate semiotic analyses of the relationships between cultural texts (literature, advertising, political discourses and so on) and social contexts, even though the texts themselves purport to transcend social determination" (180). One might extrapolate from this passage to ask the following questions: How do popular mass-produced objects and trends take on symbolic weight in American culture? What connections might we make between these commodities and American literary texts that represent historical events, debates, and individual psychology $?^{2}$ And more specifically, if also more whimsically, is there a secret symbolic relationship between Melville's Moby-Dick and the extreme machine?

If Americans of the 1850s longed for security, prosperity, and leisure, contemporary Americans apparently fantasize about physical prowess, challenges, and adventure. In "Nature," Emerson famously wrote of the effects of being outdoors, alone in the forest: "[A]ll mean egotism vanishes; I become a transparent eyeball; I am nothing; I see all” (10). In our own day the transparent eyeball has morphed into the television set and computer screen; Emerson's restorative walk in the woods is now a window-shopping stroll in the mall; the ubiquitous contact of the cell phone has replaced the solitude of Thoreau's hut. Rather than hunting whales across strange and perilous oceans for their oil, Americans drive gas-guzzling leviathans through identical neighborhoods of tract houses and strip malls. "Not that you would, but you could," proclaims an advertisement for the Nissan X-Terra. As a surrogate adventure, the extreme machine might be yet another instance of the postmodern inclination to vicarious experience and pleasure: observing baseball rather than playing it, having cybersex rather than physical intimacy, watching the travel channel rather than traveling. For, as Christopher Lasch ominously observed, "[t]oday Americans are overcome not by the sense of endless possibility but by the banality of the social order they have erected against it" (Narcissism 11).

The Walden quotation in the Suburban brochure suggests that SUV advertising strategies may be an effect of capitalism's intersection with - or commodification of-American history, geography, and fantasy. This is one way that Moby Dick and the extreme machine are linked: as emblems of historically and stylistically opposed ways of life. From the harrowing production of a natural resource to its conspicuous overconsumption: from a life of terrifying danger to one of predictable, sometimes stultifying, routine; from a sense of human frailty and insignificance in the face of natural forces to an inflated, psychologically suspect sense of power and importance; from the sublime to the banal. The extreme machine is not a vehicle for the affirmation of endless possibility because its function is to deny the fears such possibilities inspire; instead, it suggests a doomed attempt at escape from, or denial of, the social and cultural fears that motivated its purchase. "The world of commodities," writes Lasch, "takes the form of a dream world, a prefabricated environment that appeals directly to our inner fantasies but seldom reassures 
us that we ourselves have had a hand in its creation" (Minimal Self 195). Nancy Chodorow elaborates:

Personal symbols, in this view, have the characteristics of transitional phenomena that link inner and outer. They are given as cultural and presented from withoutproducts of specific historical interactions and institutions, gaining meaning within particular networks of meaning. But they are also created through personal fantasy animation from within. (196)

Melville's Moby-Dick was first published in 1851, when the American whaling industry was near its peak of productivity, having displaced the Dutch and the English (Davis, Gallmen, and Gleiter 131). Too expensive for private domestic use, sperm oil was used as an illuminant in public buildings like lighthouses and as a lubricant in factory machinery (29). A mature male sperm whale the size of Moby Dick, "a Sperm Whale of uncommon magnitude and malignity" (Melville 983), would have been a particularly valuable commodity. At sixty feet long, the very largest male could yield 100 barrels of oil. Ambergris and spermaceti were two other valuable products. The creature itself excited both awe and disgust; it was monstrous, a fish, as Ishmael insists, rather than a fellow mammal.

In addition to his "unwonted magnitude," Melville's fictional white whale is described as possessing "a peculiar snow-white wrinkled forehead, and a high pyramidical white hump" (987-988). These identify him even at long distances. He evinces an "infernal forethought of ferocity," as when he pretends to retreat and then turns upon his pursuers, "either [to] stave their boats to splinters or drive them back in consternation to their ships" (988). To contemporary readers, Melville's white whale seems less like a metaphysical villain than the hero of an embattled species fighting exploitation and extinction. The leviathan of the deeps has its human defenders in Greenpeace and Paul Watson's Sea Shepherd Conservation Society. The natural and environmental history of the whale, the rise and decline of the whaling industry, remind many of us of the unfortunate consequences of rampant consumption.

As a symbol in Feidelson's sense, the whale has been appropriated by a culture industry that is itself an international behemoth. The cinematic whale has been domesticated, inspiring nostalgia and pity rather than awe and fear. The killer whale of Free Willy! is liberated by a child in a film made for children. The title of that film alludes playfully to campaigns to free political prisoners from the Vietnam era to the present. The narrative of the extreme machine, however, is the narrative of a new cultural sublime: terrifying not in its destructive power, its mysterious grandeur, and sinister intelligence, but in its omnipresent banality and grandiose, ostentatious display.

The relationship between Moby Dick and the extreme machine is both successive and antithetical, complicated, and layered. Most obviously there is a shift from the organic to the mechanical. In Melville's novel, the white whale embodied the living, mysterious sublimity of nature, whereas the extreme machine makes of nature merely a landscape to be conquered and an oil to be consumed. Furthermore, the extreme machine's awe-inspiring size is purely physical, not uncannily meta- 
physical, as is the case with the natural sublime. There is another shift from scarcity to abundance, from the oil of a living organism to the petroleum oils of geological strata. There is a contrast in attitudes towards one's fellows: the libertarian driver of the extreme machine disdains collectivity as an impediment to the free play of individual desire; life on board whalers like the Pequod was one of collective effort based on " $[\mathrm{t}]$ he peculiar perils of [a whaling voyage] and the community of interests prevailing among a company, all of whom, high or low, depend for their profits, not upon fixed wages, but upon their common luck, together with their common vigilance, intrepity, and hard work" (948).

\section{Moby-Dick and the Narcissistic Wound}

For with little external to constrain us, the innermost necessities in our being, these still drive us on.

$$
\text { -Melville, Moby-Dick }
$$

At the beginning of Moby-Dick, Ishmael's reasons for taking ship are explicitly psychological. He is alienated and subject to inappropriately aggressive urges; he wants to knock the hats off passers-by in the street. He is suicidal, telling us that going to sea is his substitute for pistol and ball. In short, he is depressed, and in making this a precondition for the action of the novel, Melville depends upon the old association between mental illness and the ocean.

Water has yet other associations for Ishmael. It is inevitably linked to reverie, meditation, metaphysics. It is attractive not only to depressives like himself, he insists; water magnetically and even comically draws all human beings to its periphery: "They must get just as nigh the water as they possibly can without falling in" (796). Ishmael's arguments for the universal and mysterious appeal of water take the form of a series of questions, some hypothetical, others socio-historical, concluding:

\footnotetext{
Why did the old Persians hold the sea holy? Why did the Greeks give it a separate deity, and own brother of Jove? Surely all this is not without meaning. And still deeper the meaning of the story of Narcissus, who because he could not grasp the tormenting, mild image he saw in the fountain, plunged into it and was drowned. But that same image we ourselves see in all rivers and oceans. It is the image of the ungraspable phantom of life; and this is the key to it all. (797)
}

Ishmael makes this resonant allusion in the very first chapter, and in this passage Narcissus is both the self and the obliteration of the self; the most familiar of images and the most elusive; the key to meaning - the meaning of meaning — and yet "ungraspable," incomprehensible. Narcissus is implicitly invoked later in the novel as well. In chapter 99, when Ahab contemplates the doubloon he has nailed on the masthead, he sees his own reflection and ponders its significance as follows: "All are Ahab; and this round gold is but the image of the rounder globe which, like a magician's glass, to each and every man in turn but mirrors back his own mysterious self" (1254). According to Freud, narcissism is not only a perversion in which, 
like Narcissus in the myth, one falls in love with one's own image. There is also a "normal and primary narcissism" that all human infants experience, when the world seems as one with their bodies, feeding them, cleaning them, and comforting them whenever they demand it. In the course of time, particularly at weaning, the infant comes to realize that the world will not always obey his wishes - the mother is not always present and will not always appear when summoned. The feeling of helplessness that results inflicts the "narcissistic wound," a sense of injury that continues to exist in adulthood and can be activated by personal losses and failures. ${ }^{3}$

At this stage, the child may find some comfort in a teddy bear or special blanket to compensate for the mother's periodic absences. Lasch explains the symbolic importance of such objects: "Symbolism serves to invest external objects with the erotic gratification and security formerly associated with the mother, but it originates in a certain disillusionment: the discovery that the outside world does not obey the infant's whims and is not subject to his omnipotent control" (Minimal Self 194). A transitional object like the toy bear or blanket provides the child with some sense of control, of object mastery.

There is a relationship between object mastery and narcissism. Michael Rogin explains it as follows:

The sea devours and dissolves the object world; commodities provide humans with their sense of power over nature. Instead of being consumed, humans consume commodities. The white whale reverses that process. It drives Ahab back to the original human helplessness against which commodity creation defended. When Moby Dick shears off Ahab's leg, it reopens the wounds of nature's antagonism ... . Returned to infancy, Ahab was reborn a monomaniac. He inhabited the primitive desire to destroy the early source of all nurture and all disappointment.

Rogin's account here is informed by Freudian theories of primary and secondary narcissism, demonstrating how commodities and consumption mediate more primitive relationships of self and world. The loss of his leg to Moby Dick is Ahab's "narcissistic wound" - an injury to his sense of self, of wholeness, and of selfsufficiency. "In his eyes," thinks Starbuck as he regards his captain, "I read some lurid woe would shrivel me up, had I it" (973). After Ahab is violently returned to the helplessness of infancy, he develops secondary or pathological narcissism. Maddened by his loss, Ahab seeks to avenge himself, without regard to the welfare of his crew or the profits of the stockholders in the voyage. Narcissistic rage and grandiosity fuel Ahab's pursuit of the white whale. "Talk not to me of blasphemy, man," says Ahab to Starbuck. "I'd strike the sun if it insulted me" (967).

Building on Rogin's reading, we might speculate that the reversal effected by Ahab's injurious encounter with the white whale is being obsessively staged and reenacted in the contemporary consumer's desire to commandeer the whale, to cannibalize its powers, and to inhabit its intimidating bulk. This phenomenon in turn is curiously associated with shows of patriotism, as extreme machines festooned with American flags and bumper-stickers ("These colors don't run!") lumber through cities and suburbs. Since September 11th, our national equivalent of a 
narcissistic wound, the grandiosity of the Bush administration and its most chauvinistic supporters has only been exacerbated. A gigantic emblem of American economic power, the twin towers of the World Trade Center, proved as vulnerable to assault and trickery as Fasolt and Fafner, the two giants who guard the gold in Wagner's Ring.

\section{Narcissistic Rage and Grandiosity}

Not by beef, or by bread, are giants made or nourished. -Melville, Moby-Dick

Since World War II, according to Lasch and his psychiatric sources, the "character disorders" have superseded the classical neuroses treated and described by Freud. Narcissists of one kind or another have always been around, but narcissistic traits have never before been so encouraged by the culture. As an inhabitant of late capitalism and postmodern culture, the contemporary narcissist is both a psychologically damaged product of contemporary economic and social conditions and a paradigm for success in a depthless, image-driven society, itself unmoored from history. Emotionally shallow, socially manipulative, grandiose, and constantly driven to protect a fragile sense of self-esteem, the narcissist attempts to stave off a pervasive sense of emptiness with visible achievements, superficial relationships, and the distractions of television, shopping, and spectator sports. Recent novels, such as American Psycho and The Corrections, vividly represent contemporary narcissism, while celebrity businessmen like Donald Trump and Hummer-driving movie stars like Arnold Schwarzenegger demonstrate how ostentation and banality can coalesce.

Lasch explains the interrelation of individual psychology and sociology as follows:

Every age develops its own peculiar forms of pathology which express in exaggerated form its underlying character structure. In Freud's time, hysteria and obsessional neurosis carried to extremes the personality traits associated with the capitalist order at an earlier stage in its development-acquisitiveness, fanatical devotion to work, and a fierce repression of sexuality. (Narcissism 34)

Conscious of the need for historical specificity, Lasch does distinguish the narcissist of Melville's day, as represented in Ahab or Ishmael, from the contemporary version. "The egomaniacal, experience-devouring, imperial self [of the nineteenth century]," he writes, "regresses into a grandiose, narcissistic, infantile, empty self [of the twentieth century]" (12). Unlike Ahab, the contemporary narcissist is incapable of "an idée fixe, a neurotic compulsion, a "magnificent obsession"” (99). Ishmael's narcissism is also different, roused by natural forces - the reflecting water, the limitless sea-rather than shaped and mediated by consumer culture, with its constant interpellations of desire.

Unlike his nineteenth-century counterparts, the contemporary narcissist depends for the fulfillment of basic needs (food, shelter, transportation, electricity, 
medicine) upon large, remote, and bureaucratic corporations and branches of government. It is in part this pervasive dependence, Lasch thinks, itself reminiscent of infantile helplessness, that exacerbates any innate, individual inclination to narcissism. Another factor is a massive change in the object world itself, no longer the nature that humans conquer in order to alleviate a sense of helplessness - the whale that Ahab seeks to kill. Along Marxist lines, Lasch distinguishes the child's transitional objects, the blankets and teddy bears, from the world of commodities:

Lacking any transitional character, the commodity world stands as something completely separate from the self; yet it simultaneously takes on the appearance of a mirror of the self, a dazzling array of images in which we can see anything we wish to see. Instead of bridging the gap between the self and its surroundings, it obliterates the difference between them. (Minimal Self 195-196)

By taking on "the appearance of a mirror of the self," commodity culture exacerbates the culture of narcissism. By providing consumers with a "dazzling array of images," it emphasizes surface rather than depth and the present rather than any sense of historical continuity. The universe of disposable commodities, constantly changing in accord with trends and innovations, in turn erodes a sense of self that endures and changes over time, encouraging instead the sense of an "identity" that can be altered at will. This is because "the consumer knows the world . . . largely through insubstantial images and symbols that seem to refer not so much to a palpable, solid, and durable reality as to his inner psychic life, itself experienced not as an abiding sense of self but as reflections glimpsed in the mirror of his surroundings" (Minimal Self 34, emphasis added). Such an image and symbol is the extreme machine.

Like the infant who expects every demand to be satisfied, the narcissist's symptomatic sense of entitlement stems from an unconscious assumption that he is special - that his needs and wishes outweigh those of other people and that they should recognize this and behave accordingly. This sensibility is called grandiosity, and it is a hallmark of the narcissistic personality. On an individual level, grandiosity may manifest itself in a mad quest, like Ahab's vengeance on the whale, or, more commonly, in an unconscious sense of privilege and superiority even in minor matters. It may express itself in lofty indifference or uncontrolled rage. In The Immortal Class, for example, bike courier Travis Hugh Culley describes hostile encounters between cyclists and SUV drivers, one of which resulted in a death. "The Tahoe that ran down Tommy was carrying only one man," Culley writes. "Yet something gave that man the idea that he alone, because he was driving, owned the road" (294-295). That "something" was probably the Chevy Tahoe itself, looming over the cyclist, allowing its owner to express his anger with the same sense of overwhelming, disdainful power that a child may feel upon crushing a bug.

Grandiosity often manifests itself in a rejection of limits - personal, natural, and social. If the popularity of the extreme machine is a symptom of our collective narcissism, with its accompanying sense of grandiosity, it signifies something more than individual pathology. Might a psychological trait like grandiosity become part of a national ideology? Does psychology license such a linkage? In fact it does. In 
"The Future of an Illusion" Freud explains how citizenship in a powerful nation gives everyone-even poor, downtrodden members of that nation-a sense of power, prestige, and self-worth:

The satisfaction which the ideal offers to the participants in the culture is thus of a narcissistic nature; it rests on their pride in what has already been successfully achieved. To make the satisfaction complete calls for a comparison with other cultures which have aimed at different achievements and have developed different ideals. On the strength of these differences every culture claims the right to look down on the rest. In this way cultural ideals become a source of discord and enmity between different cultural units, as can be seen most clearly in the case of nations. The narcissistic satisfaction provided by the cultural ideal is also among the forces which are successful in combating the hostility to culture within the cultural unit. (691-692).

The extreme machine, large beyond all reason and larger every year, is a manifestation of grandiosity, the sense of entitlement, and disdain for limits - including speed limits. Like the ill-fated Titantic, also initially celebrated for its safety, the monstrous luxury truck suggests a kind of hubris, an exaggerated - and unfounded-confidence in human mastery of that wild nature so revered by writers of the American Renaissance. One of the symbolic meanings the extreme machine has accreted is accordingly political. The car one drives has always been at least suggestive of its owner's politics and social attitudes, but in the era of extreme machines the spectrum has become simplified into a binary us-or-them, as defenders of these vehicles deride their critics as "liberals" or "hippies."

The owners of extreme machines assert that their personal freedom would be abridged by any regulation of their desires. On the floor of the Senate, Trent Lott objected to increases in CAFÉ (Corporate Average Fuel Economy), saying, "What about choice? This is still America!" (Rosenbaum 28). Appearing on the 2001 Earth Day debate on the TV show Politically Incorrect, guest Erin Shannon protested: "Detroit is responding to demand. What people want are big SUVs. They [the auto makers] don't do it because that's what the car corporations want [people] to do. I can pay for a Suburban, so why shouldn't I be able to drive a Suburban? The government should have no say in what kind of vehicle I drive." In the rhetoric of Lott and Shannon, freedom is inseparable from - indeed, indistinguishable from consumption. It is implicitly aligned with economic power and "discretionary income." Consumption in turn is imagined as a purely individual matter, regardless of social consequences. Perhaps this explains the naivete, the rage, and the curiously childlike tone manifested by some defenders of extreme machines. As Lasch explained, the mirroring world of commodities obliterates rather than bridges the gap between self and world. The extreme machine is a fetish, compensation for a lack that is so pervasive, relentless, and gnawing that it can only be attested to (since it cannot be filled) by a symbol that in turn conveys the alienation of postmodern American life.

Chodorow warns of the political ill-effects of narcissism: "The narcissistic mode of relating and of drive gratification based on the pleasure principle precludes 
those very intersubjective relationships that should form the core of any social and political vision" (242). The libertarian celebration of selfishness, derived largely from Ayn Rand, has infiltrated not only the Republican right wing but public discourse in general, as American "freedom"- once meaning the freedoms listed in the Bill of Rights - is reconfigured as merely the freedom to consume without regulation, interference, or even criticism. "Freedom" is thus defined against the government and in solidarity with the behemoth corporations that make automobiles and control the mass media - further licensing the narcissist's identification with the extreme machine.

Is there a way out of narcissism? According to Lasch:

The best hope for emotional maturity ... of ordinary unhappiness as opposed to crippling mental torment - appears to lie in a creative tension between separation and union, individuation and dependence. It lies in a recognition of one's need for and dependence on people who nevertheless remain separate from oneself and refuse to submit to one's whims. (Minimal Self 177-178)

As a culture, the United States continues to suffer from an inflated sense of selfworth, a posture that alienates nations around the world, our allies as well as our enemies. For American society, as for individual patients in therapy, overcoming narcissism would mean an acceptance of limits - limits on individual gratification in a social setting, on our use of fossil fuels, on what and how much we consume, and on our authority in international relations. As Jean Baudrillard asks: "What has become of the challenge sketched out by Tocqueville: can a nation strike a pact of greatness on the basis of each individual's banal interest alone?" (89).

\section{Notes}

${ }^{1}$ In more recent Hollywood movies the extreme machine has become an indispensable accessory, distinguishing flashy new money from the stodgy old money of Cadillacs and Continentals. In Don't Say a Word, for example, a psychiatrist drives a silver Range Rover through traffic jams to the rescue of his daughter, much as the hero of a 1950s Western might have done on his white steed. At the end of Unfaithful, a married couple sits in a SUV near a police station, discussing a possible flight to Mexico. They are not contemplating a vacation in Acapulco; they are complicit in a murder and in fear of arrest. We, the audience, know from all the advertisements and commercials that their SUV could get them to Mexico if they decided to make a run for it. They could take the back roads, go down arroyos and over limestone bluffs. If Thelma and Louise had driven a Toyota Sequoia, they too might have made a successful escape.

${ }^{2}$ Do the symbols of the American Renaissance anticipate the symbols of brand names? If, as Adorno writes of Wagner, the leitmotif is the ancestor of the commercial jingle, is the A of Hawthorne's Scarlet Letter the prefiguration of a logo, like the CK of Calvin Klein?

${ }^{3}$ According to Freud:

The early efflorescence of infantile sexual life is doomed to extinction because its wishes are incompatible with reality and with the inadequate stage of development which the child has reached. That efflorescence comes to an end in the most distressing circumstances and to the accompaniment of the most painful feelings. Loss of 
love and failure leave behind a permanent injury to self-regard in the form of a narcissistic scar, which in my opinion contributes more than anything to the sense of inferiority so common in neurotics. ("Beyond the Pleasure Principle" 603, emphasis added)

\section{Works Cited}

Baudrillard, Jean. America. London: Verso, 1989.

Bradsher, Keith. High and Mighty: SUVs: The World's Most Dangerous Vehicles and How They Got That Way. New York: Public Affairs, 2002.

Chodorow, Nancy J. The Power of Feelings: Personal Meaning in Psychoanalysis, Gender, and Culture. New Haven, CT: Yale University Press, 2001.

Culley, Travis Hugh. The Immortal Class: Bike Messengers and the Cult of Human Power. New York: Villard Books, 2001.

Davis, Lance E., Robert E. Gallmen, and Karin Gleiter. In Pursuit of Leviathan: Technology, Institutions, Productivity, and Profits in American Whaling 1816-1906. Chicago: University of Chicago Press, 1997.

Don't Say a Word. Dir. Gary Fleder. Perf. Michael Douglas. 20th Century Fox, 2001.

Emerson, Ralph Waldo. "Nature." Essays and Lectures. New York: Library of America, 1983. 9-49.

Feidelson, Charles. Symbolism and American Literature. 1953. Chicago: University of Chicago Press, 1979.

Freud, Sigmund. "Beyond the Pleasure Principle." The Freud Reader. Ed. Peter Gay. New York: Norton, 1995. 594-626.

—. "The Future of an Illusion." The Freud Reader. Ed. Peter Gay. New York: Norton, 1995. 686-722.

Lasch, Christopher. The Culture of Narcissism: American Life in an Age of Diminishing Expectations. New York: Norton, 1979.

-. The Minimal Self: Psychic Survival in Troubled Times. New York: Norton, 1984.

Melville, Herman. Redburn, White-Jacket, Moby-Dick. New York: New American Library, 1983.

Politically Incorrect. Host Bill Maher. ABC. 22 Apr. 2001.

Reising, Russell. The Unusable Past: Theory and the Study of American Literature. New York: Methuen, 1986.

Roberts, Paul. "Bad Sports: Or How We Learned to Stop Worrying and Love the SUV." Harper's Magazine April 2001: 69-75.

Rogin, Michael Paul. Subversive Genealogy: The Politics and Art of Herman Melville. Berkeley: University of California Press, 1985.

Rosenbaum, David E. "Senate Deletes Higher Mileage Standard in Energy Bill." New York Times 14 Mar. 2002: 28.

Unfaithful. Dir. Adrian Lyne. Perf. Richard Gere and Diane Lane. 20th Century Fox, 2002. 